\title{
Retraction Note: GIS-based niche suitability model of rice breeding and cultivation and evaluation of multi-suitability of cultivated land
}

\author{
Yexing $\operatorname{Pan}^{1}$
}

Published online: 6 December 2021

C) Saudi Society for Geosciences 2021

Retraction Note: Arabian Journal of Geosciences (2021) 14: 932

https://doi.org/10.1007/s12517-021-07166-4

The Editor-in-Chief and the Publisher have retracted this article because the content of this article is nonsensical. The peer review process was not carried out in accordance with the Publisher's peer review policy. The author has not responded to correspondence regarding this retraction.

The original article can be found online at https://doi.org/10.1007/ s12517-021-07166-4.

Yexing Pan

jilinnong@sohu.com

1 Department of Agronomy, Jilin Agricultural Science and Technology University, Jilin 132101, China 